\title{
Distribution and occurrence of lithium in high-alumina-coal fly ash
}

Hu, Pengpeng; Hou, Xinjuan; Zhang, Jianbo; Li, Shaopeng; Wu, Hao; Damø, Anne Juul; Li, Huiquan; Wu, Qisheng; Xi, Xinguo

Published in:

International Journal of Coal Geology

Link to article, DOI:

10.1016/j.coal.2018.02.011

Publication date:

2018

Document Version

Peer reviewed version

Link back to DTU Orbit

Citation (APA):

Hu, P., Hou, X., Zhang, J., Li, S., Wu, H., Damø, A. J., Li, H., Wu, Q., \& Xi, X. (2018). Distribution and occurrence of lithium in high-alumina-coal fly ash. International Journal of Coal Geology, 189, 27-34. https://doi.org/10.1016/j.coal.2018.02.011

\section{General rights}

Copyright and moral rights for the publications made accessible in the public portal are retained by the authors and/or other copyright owners and it is a condition of accessing publications that users recognise and abide by the legal requirements associated with these rights.

- Users may download and print one copy of any publication from the public portal for the purpose of private study or research.

- You may not further distribute the material or use it for any profit-making activity or commercial gain

- You may freely distribute the URL identifying the publication in the public portal 


\section{Accepted Manuscript}

Distribution and occurrence of lithium in high-alumina-coal fly ash

Pengpeng $\mathrm{Hu}$, Xinjuan Hou, Jianbo Zhang, Shaopeng Li, Hao Wu, Anne Juul Damø, Huiquan Li, Qisheng Wu, Xinguo Xi

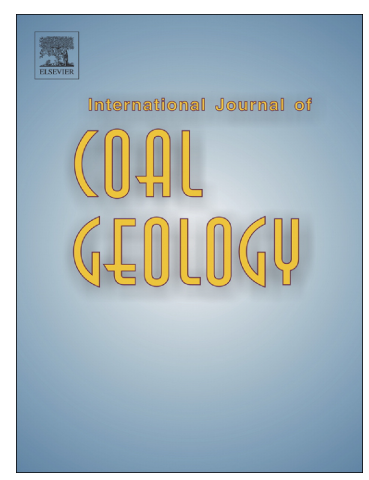

PII: $\quad$ S0166-5162(17)30991-6

DOI: $\quad$ doi:10.1016/j.coal.2018.02.011

Reference: COGEL 2969

To appear in: $\quad$ International Journal of Coal Geology

Received date: $\quad 24$ November 2017

Revised date: $\quad 10$ February 2018

Accepted date: $\quad 10$ February 2018

Please cite this article as: Pengpeng $\mathrm{Hu}$, Xinjuan Hou, Jianbo Zhang, Shaopeng $\mathrm{Li}$, Hao Wu, Anne Juul Damø, Huiquan Li, Qisheng Wu, Xinguo Xi, Distribution and occurrence of lithium in high-alumina-coal fly ash. The address for the corresponding author was captured as affiliation for all authors. Please check if appropriate. Cogel(2018), doi:10.1016/j.coal.2018.02.011

This is a PDF file of an unedited manuscript that has been accepted for publication. As a service to our customers we are providing this early version of the manuscript. The manuscript will undergo copyediting, typesetting, and review of the resulting proof before it is published in its final form. Please note that during the production process errors may be discovered which could affect the content, and all legal disclaimers that apply to the journal pertain. 


\title{
Distribution and occurrence of lithium in high-alumina-coal fly
}

\author{
ash \\ Pengpeng $H u^{a, b}$, Xinjuan Hou, ${ }^{a, b}$, Jianbo Zhang ${ }^{a}$, Shaopeng $\mathrm{Li}^{a, *}{ }^{*}$, Hao $\mathrm{Wu}^{c}$, Anne Juul Dam $\phi^{c}$, Huiquan Li $i^{a, b, ~ *}$, \\ Qisheng $W u^{d}$, Xinguo $\mathrm{Xi}^{d}$ \\ ${ }^{a}$ CAS Key Laboratory of Green Process and Engineering, National Engineering Laboratory for Hydrometallurgical Cleaner \\ Production Technology, Institute of Process Engineering, Chinese Academy of Sciences, Beijing 100090, China \\ ${ }^{b}$ University of Chinese Academy of Sciences, Beijing 100049, China \\ ${ }^{c}$ Department of Chemical and Biochemical Engineering, Technical University of Denmark, DK-2800, Kgs., Lyngby, Denmark \\ ${ }^{d}$ Yancheng Institute of Technology, Jiangsu 224051, China
}

\footnotetext{
${ }^{*}$ Corresponding author at: CAS Key Laboratory of Green Process and Engineering, National Engineering Laboratory for Hydrometallurgical Cleaner Production Technology, Institute of Process Engineering, Chinese Academy of Sciences, Beijing 100090, China. E-mail address: shpli@ipe.ac.cn (S. Li). E-mail address: hqli@ipe.ac.cn (H. Li).
} 


\begin{abstract}
High-alumina-coal fly ash (HAFA) with a high Li content is regarded as a potential resource for $\mathrm{Li}$ production. To support the development of $\mathrm{Li}$ recovery technology from HAFA, the distribution and modes of occurrence of $\mathrm{Li}$ in HAFA were investigated. HAFA was separated into magnetic particles, glass, and mullite+corundum+quartz (MCQ) using an acid-alkali combination method. $79-94 \%$ of the $\mathrm{Li}$ was found in glass, with the remaining $5-16 \%$ and $<5 \%$ of $\mathrm{Li}$ in $\mathrm{MCQ}$ and magnetic particles, respectively. Chemical state imaging of Li in HAFA, magnetic particles, and MCQ was obtained using time-of-flight secondary ion mass spectrometry (TOF-SIMS). Lithium was found to be relatively uniformly distributed in the HAFA particles and strongly correlated with $\mathrm{Al}$ and $\mathrm{Si}$. Possible formation pathways of $\mathrm{Li}$ in the glass phase were proposed. The energy differences between reactants and products $(\Delta \mathrm{E})$ calculated using the generalized gradient approximation (GGA) method indicated that $\mathrm{Li}$ occurred in $\mathrm{Q}^{3}(0 \mathrm{Al})$ and $\mathrm{Q}^{3}(1 \mathrm{Al})$ structures by reacting with $\mathrm{Q}^{4}(0 \mathrm{Al})$ and $\mathrm{Q}^{4}(1 \mathrm{Al})$. Based on the experimental and simulation results, we propose extracting $\mathrm{Li}$ during the pre-desilication process by dissolving the glass phase.
\end{abstract}

Key words: High-alumina-coal fly ash; lithium; mode of occurrence; TOF-SIMS; molecular simulation 


\section{Introduction}

High-alumina coal (HAC) has been found in the northern part of Shanxi Province and in the middle-western part of Inner Mongolia, China, including in the Heidaigou (Dai et al., 2006), Haerwusu (Dai et al., 2008), Guanbanwusu (Dai et al., 2012a), Adaohai (Dai et al., 2012b). High-alumina-coal fly ash (HAFA), the combustion product of HAC, has been attracting a large amount of attention due to its high alumina content $(>35 \%)$ (Chen, 2005). Currently, the annual production of HAFA in China is approximately $20 \mathrm{mt}$, which is used primarily in the production of cement, bricks and tiles, and concrete, and less than $20 \%$ of this HAFA is utilized (Sun, 2016). The unutilized HAFA is treated by stockpiling, which may cause environmental concerns. Extraction and utilization of Al (Li et al., 2014), Ga (Li et al., 2016), and Li (Hou et al., 2015) are good alternatives to the disposal of HAFA with various benefits related to the economy, environment, and national security (Dai and Finkelman, 2017; Seredin et al., 2013). In particular, HAFA contains a relatively high content of $\mathrm{Li}$, approximately $250-1400 \mu \mathrm{g} / \mathrm{g}\left(\mathrm{Li}_{2} \mathrm{O}\right.$ content $0.06-0.30 \mathrm{wt}$ \% \%) (Dai et al., 2010; Gong et al., 2016), which is comparable to industrial grade Li-bearing pegmatite deposits in China, which have $\mathrm{Li}_{2} \mathrm{O}$ contents of $0.2 \%$ (DZ/T 0203-2002, 2003)

To support the development of $\mathrm{Li}$ recovery technology from HAFA, understanding the modes of occurrence of Li in HAFA is necessary. The modes of occurrence of $\mathrm{Li}$ have been focused on HAC. Li has been found mainly in a form of isomorphic chlorite in the Guanbanwusu coal (Dai et al., 2012a) and in aluminosilicates in the Haerwusu coal (Dai et al., 2008). However, HAFA has undergone high-temperature transformations that would change the mineral phases and the modes of occurrence of $\mathrm{Li}$ in HAC. Li was found to be enriched in the glass phase of HAFA from the Jungar Power Plant (Dai et al., 2010). Modes of occurrence of $\mathrm{Li}$ in the glass phase of HAFA should be investigated.

This paper investigates the distribution and modes of occurrence of Li in HAFA 
produced in Inner Mongolia and Shanxi Province, China. HAFA samples were separated into magnetic particles, mullite+corundum+quartz (MCQ), and their glass phase by magnetic separation and an acid-alkali combination method (leached by $\mathrm{HCl}$ and $\mathrm{NaOH}$ solutions, respectively). The distributions of $\mathrm{Li}$ and the major elements in the three phases were determined based on chemical compositional analyses of the phases and mass-balance calculations. Time-of-flight secondary ion mass spectrometry (TOF-SIMS) was used to observe the distributions of $\mathrm{Li}, \mathrm{Al}, \mathrm{Si}$, and $\mathrm{Fe}$ in the HAFA samples, magnetic particles, and MCQ. Furthermore, the modes of occurrence of $\mathrm{Li}$ in the HAFA were proposed based on the simulation of possible reactions between $\mathrm{Li}_{2} \mathrm{O}$ and the four model compounds in the glass phase of the HAFA. Finally, a method for recovering Li from HAFA was proposed.

\section{Samples and methods}

The sources of the HAFA (denoted IM-1, IM-2, SX-1, and SX-2) and the general situations for the corresponding power plants are listed in Table 1. The locations of the power plants are shown in Fig. 1. The samples were collected from precipitators. The chemical agents that were used in the experiments were all of analytical grade. Distilled water was used exclusively.

\section{Table 1}

Sources of the HAFA samples and general situations for the corresponding power plants

\begin{tabular}{llll}
\hline Samples & Sources & Power plant & Capacity \\
\hline IM-1 & Inner Mongolia & Guohua Jungar Power Plant & $4 \times 330 \mathrm{MW}$ \\
IM-2 & Inner Mongolia & Datang Togtoh Power Plant & $8 \times 600 \mathrm{MW}+2 \times 300 \mathrm{MW}$ \\
SX-1 & Shanxi, & $\begin{array}{l}\text { Datong 2nd Power Plant (first } \\
\text { phase project) }\end{array}$ & $6 \times 200 \mathrm{MW}$ \\
& & Yangquan 2nd Power Plant & $4 \times 300 \mathrm{MW}$ \\
SX-2 & Shanxi & . & \\
\hline
\end{tabular}

The HAFA samples were all produced in pulverized coal boilers. The feed coal in the listed power plants are all from local sources. 


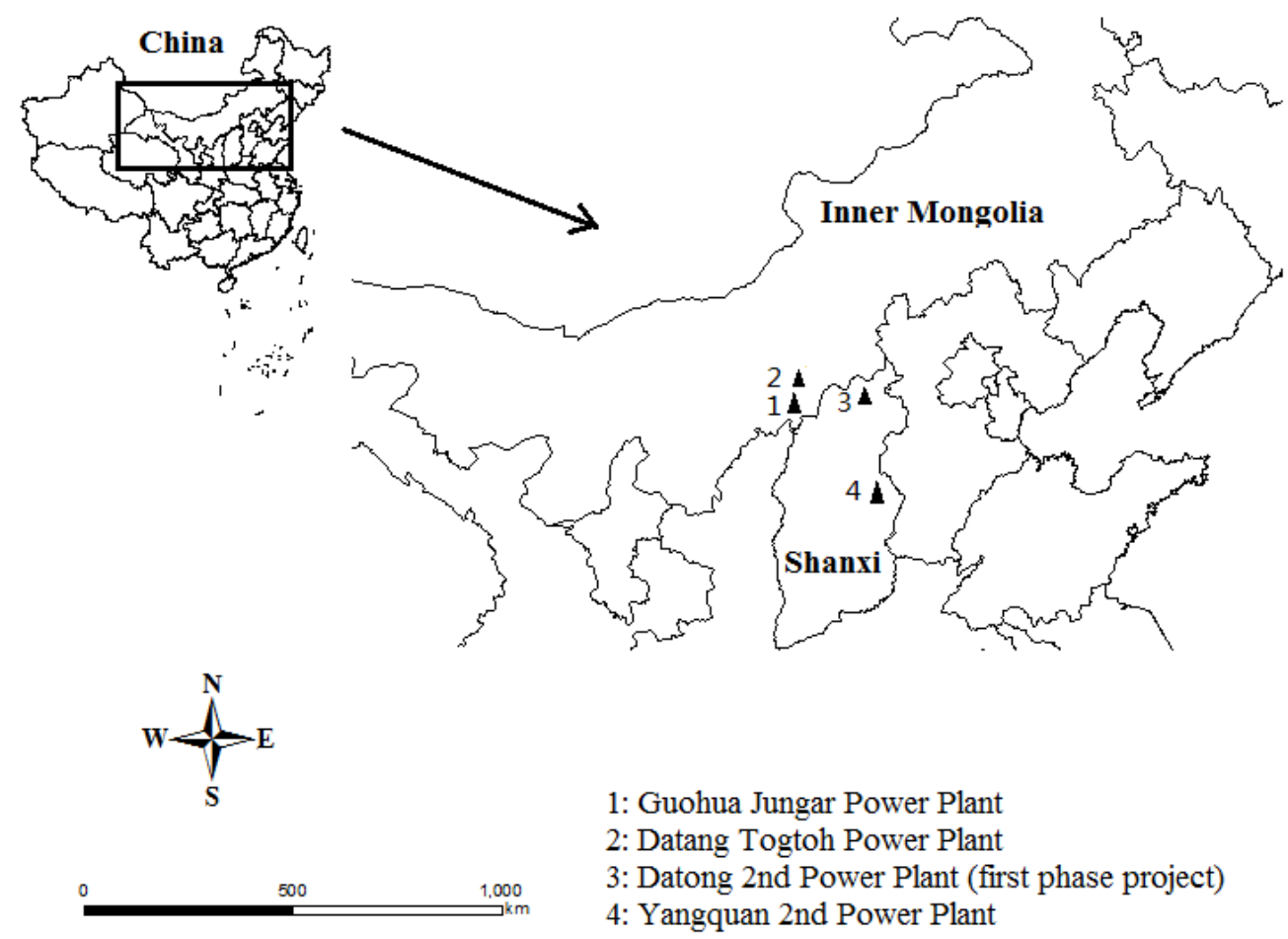

Fig. 1. Locations of the power plants

(Single fitting image)

To study the distributions of elements in different phases, each HAFA sample was separated into magnetic particles, glass, and MCQ. Prior to phase separation, the HAFA samples were dried at $105{ }^{\circ} \mathrm{C}$ for 5 hours and were ground using a ball mill at $300 \mathrm{rpm}$ for 2 hours. The magnetic particles were first separated from the HAFA using a hand magnet in water (Chen et al., 2017; Dai et al., 2010). HF solution is commonly used to dissolve the glass phase (Dai et al., 2010). However, HF can also decompose mullite in HAFA (Li et al., 2011; Tripathy et al., 2015), and both the reactant (HF) and product $\left(\mathrm{H}_{2} \mathrm{SiF}_{6}\right)$ are highly corrosive and toxic. Thus, an alternative acid-alkali combination method, was applied to dissolve the glass phase (Zhang et al., 2016; Zhang et al., 2006). The details of the method are shown in Fig. 2 and Table 2. The solid residues from the acid-alkali combination method, mainly containing MCQ, were filtered and dried. 


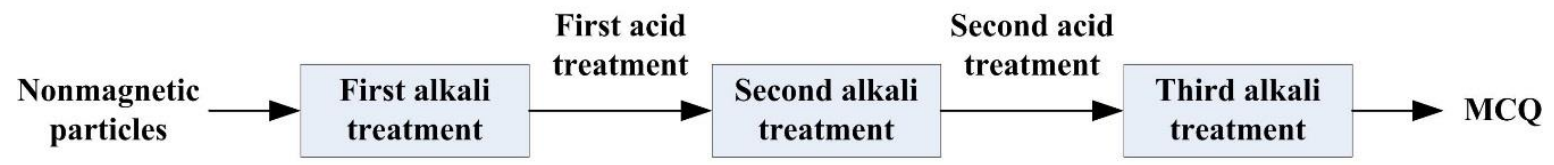

Fig. 2. Flowchart of the acid-alk ali combination method

(Single fitting image)

Table 2

Conditions for the acid-alkali combination method

\begin{tabular}{ccccc}
\hline & \multicolumn{4}{c}{ Conditions } \\
\cline { 2 - 5 } & $\begin{array}{c}\text { Temperature } \\
\left({ }^{\circ} \mathrm{C}\right)\end{array}$ & $\begin{array}{c}\text { Ratio of liquid to } \\
\text { solid }(\mathrm{ml} / \mathrm{g})\end{array}$ & $\begin{array}{c}\text { Concentration of } \\
\mathrm{NaOH} / \mathrm{HCl}(\mathrm{g} / \mathrm{L})\end{array}$ & $\begin{array}{c}\text { Time } \\
(\mathrm{min})\end{array}$ \\
\hline First alkali treatment & 95 & 3 & 240 & 80 \\
First acid treatment & 75 & 4 & 100 & 60 \\
Second alkali treatment & 80 & 5 & 120 & 35 \\
Second acid treatment & 75 & 4 & 100 & 60 \\
Third alkali treatment & 80 & 5 & 120 & 60 \\
\hline
\end{tabular}

All treatments were duplicated. In each round, the amount of raw HAFA was approximately $100 \mathrm{~g}$. The acid and alkali that are reported in the table are hydrochloric acid and a sodium hydrate solution, respectively.

The mass fractions of the three phases (magnetic particles, glass, and MCQ) in the HAFA were quantified using the measured weights of the HAFA, magnetic particles and MCQ, and mass balance calculations (see Eq. 1, Eq. 2, and Eq. 3). X-ray fluorescence spectrometry (XRF, AXIOS-MAX, 50 kV, $60 \mathrm{~mA}$ ) (Zhang et al., 2017) was used to determine the contents of major element oxides in the HAFA, magnetic particles and MCQ. To determine the contents of $\mathrm{Li}$ in the HAFA, magnetic particles, and $\mathrm{MC}$, approximately $0.1 \mathrm{~g}$ of the samples were first subjected to microwave digestion at $210{ }^{\circ} \mathrm{C}$ for 20 min with the addition of $1 \mathrm{~mL} \mathrm{HF}\left(40\right.$ wt. \%) $+2 \mathrm{~mL} \mathrm{H}_{2} \mathrm{O}_{2}$ (30 wt. \%) + 5 mL $\mathrm{HNO}_{3}(65$ wt. \%) (Low and Zhang, 2012). The digested samples were then diluted and analyzed using an Inductively Coupled Plasma Optical Emission Spectrometer (ICP-OES, Thermo Fisher Scientific, iCAP 6300) (Zhang et al., 2017). The elements in the glass phase were not directly measured but were determined based on Eq. 4. The distributions of Li and some major element oxides in 
the glass phase, magnetic particles, and MC were calculated in terms of $\frac{f_{g} G_{i}}{W_{i}} \times 100 \%$, $\frac{f_{f} F_{i}}{W_{i}} \times 100 \%$ and $\frac{f_{m} M_{i}}{W_{i}} \times 100 \%$, respectively. The phase compositions of the HAFA were examined with an X-ray diffractometer (XRD, Empyrean, CuKa, $40 \mathrm{kv}, 40 \mathrm{~mA}$ ) using $\mathrm{Cu}-\mathrm{K} \alpha$ radiation $(\lambda=1.54056 \AA, 40 \mathrm{~mA}$ and $40 \mathrm{kV})$ at a scanning range of 5$50{ }^{\circ} \mathrm{C}$. The particle sizes were analyzed using a Malvern Mastersizer Hydro $2000 \mathrm{MU}$ (Malvern Instruments Ltd). Loss on ignition (LOI) was determined by heating the samples at $950{ }^{\circ} \mathrm{C}$ for $1 \mathrm{~h}$.

$$
\begin{aligned}
& \mathrm{f}_{f}=\frac{m_{f}}{m_{H A F A}} \\
& \mathrm{f}_{m}=\frac{m_{m}}{m_{H A F A}} \\
& \mathrm{f}_{g}=1-\mathrm{f}_{f}-\mathrm{f}_{m}
\end{aligned}
$$

where $f_{f}, f_{m}$, and $f_{g}$ represent the mass fractions of magnetic particles, MCQ, and glass in the HAFA, respectively. $\mathrm{m}_{\mathrm{HAFA}}, \mathrm{m}_{\mathrm{f}}$, and $\mathrm{m}_{\mathrm{m}}$ are the total mass of the HAFA, the total mass of magnetic particles, and the total mass of MCQ, respectively.

$$
G_{i}=\left(\mathrm{W}_{i}-f_{f} F_{i}-f_{m} M_{i}\right) / f_{g} \quad \text { Eq. } 4
$$

where $W_{i}, F_{i}, M_{i}$, and $G_{i}$ represent the mass fractions of element $i$ in the HAFA, magnetic particles, MCQ, and glass, respectively.

To study the coordinate structure of $\mathrm{Si}$ in the HAFA, ${ }^{29} \mathrm{Si}$ solid-state-magic angle-spinning nuclear magnetic resonance (MAS NMR, AVANCE III HD 500, Bruker BioSpin $\mathrm{GmbH}$ ) characterization was conducted. The spectra were obtained at a frequency of $119.13 \mathrm{MHz}$ under a single pulse with a spin rate of $8 \mathrm{kHz}$ by loading the samples into a rotor with a 6 - $\mathrm{mm}$ probe. The spectra were obtained with 90 -degree pulses of 6- $\mu \mathrm{m}$ lengths and recycle times of 5 seconds. The free induction decay (FID) was 0.01 seconds.

The chemical state imaging of Li in HAFA has been challenging due to its tracelevel content and light atomic weight. Time-of-flight secondary ion mass spectrometry (TOF-SIMS 5-100, ION-TOF GmbH) is one of the most highly sensitive surface analytical tools that is capable of detecting ppm levels for most elements (including Li) and surface species (Hayashi et al., 2010). It has been applied in studies on coal and coal ashes (Dai et al., 2000; Hayashi et al., 2010; Hou et al., 
1995). This technique provides information on the elemental distribution not only at the surface but also in the interiors of HAFA particles. The samples (HAFA, magnetic particles, and MC) were first mixed with resins. After molding, cutting, grinding, and polishing, samples with sizes of $12 \mathrm{~mm} \times 12 \mathrm{~mm} \times 2 \mathrm{~mm}$ (length $\times$ width $\times$ height) and smooth surfaces were obtained. The polished samples were analyzed by rastering a $30 \mathrm{keV} \mathrm{Bi}_{1}{ }^{+}$or $\mathrm{Bi}_{3}{ }^{++}$primary ion beam with an incidence angle of $45^{\circ}$ over a $30-100 \mu \mathrm{m} \times 30-100 \mu \mathrm{m}$ area on a sample surface. The spot size of the primary ion beam was approximately $200 \mathrm{~nm}$. The positive secondary ions were collected. The range of masses was 0-1000 amu.

Generalized gradient approximation (GGA) for the exchange-correlation potential (PW91) (Perdew et al., 1996) with a double-numeric-quality basis set with d-polarization functions (DNP) was performed to optimize model compounds, which are the representatives of different coordinate structures of $\mathrm{Si}$ in the glass phase of HAFA. The Ortmann, Bechstedt, and Schmidt (OBS) method (Ortmann et al., 2006) provides a good compromise between the cost of first principle evaluation of the dispersion terms and the need to improve non-bonding interactions in the standard DFT description. In all GGA/PW91 calculations, the OBS method was used for DFT dispersion corrections (DFT-D) (Ortmann et al., 2006). The threshold values of the convergence criteria were $1.0 \times 10^{-5} \mathrm{Ha}$ for energy, $0.002 \mathrm{Ha} / \AA$ for the maximum force, $0.005 \AA$ for the maximum displacement, and $0.05 \mathrm{GPa}$ for maximum stress. The energy differences between products and reactants $(\Delta \mathrm{E})$ for each reaction were determined using Eq. 5.

$$
\Delta \mathrm{E}=\sum E_{\text {products }}-\sum E_{\text {reactants }}
$$

Eq. 5

\section{Results and discussion}

\subsection{Properties of the HAFA}

As shown in Table 3, the $\mathrm{Al}_{2} \mathrm{O}_{3}$ contents of the four HAFA samples were $>35$ wt. \%. The XRD patterns of the HAFA that are shown in Fig. 3 reveal mullite, corundum, and glass (presented by the hump at 20-25 degrees) as the main phases of 
IM-1 and IM-2; mullite, quartz, and glass are the main phases of SX-1 and SX-2. The particle size distributions for IM-1, IM-2, SX-1, and SX-2 were determined to be $\mathrm{d}(0.5)=21.6 \mu \mathrm{m}, 59.2 \mu \mathrm{m}, 87.2 \mu \mathrm{m}$, and $44.7 \mu \mathrm{m}$, respectively.

\section{Table 3}

Chemic al composition of the major elements and $\mathrm{Li}$ in the HAFA

\begin{tabular}{cccccccccc}
\hline Composition & $\mathrm{Al}_{2} \mathrm{O}_{3}$ & $\mathrm{SiO}_{2}$ & $\mathrm{CaO}$ & $\mathrm{TiO}_{2}$ & $\mathrm{Fe}_{2} \mathrm{O}_{3}$ & $\mathrm{Na}_{2} \mathrm{O}$ & $\mathrm{MgO}$ & $\mathrm{Li}$ & $\mathrm{LOI}$ \\
\hline $\mathrm{IM}-1$ & 50.14 & 39.17 & 3.07 & 2.26 & 1.47 & 0.17 & 0.17 & 412 & 1.77 \\
$\mathrm{IM}-2$ & 47.84 & 45.19 & 1.52 & 1.49 & 1.24 & 0.08 & 0.16 & 375 & 1.55 \\
$\mathrm{SX}-1$ & 36.63 & 48.41 & 4.46 & 1.19 & 3.31 & 0.13 & 0.44 & 266 & 3.64 \\
$\mathrm{SX}-2$ & 37.85 & 50.10 & 1.61 & 1.68 & 2.76 & 0.20 & 0.37 & 267 & 3.83 \\
\hline
\end{tabular}

The compositions of the major elements are presented as oxides. The contents of oxides and $\mathrm{Li}$ are reported in wt. $\%$ and $\mu \mathrm{g} / \mathrm{g}$, respectively. LOI is reported in wt. \%.

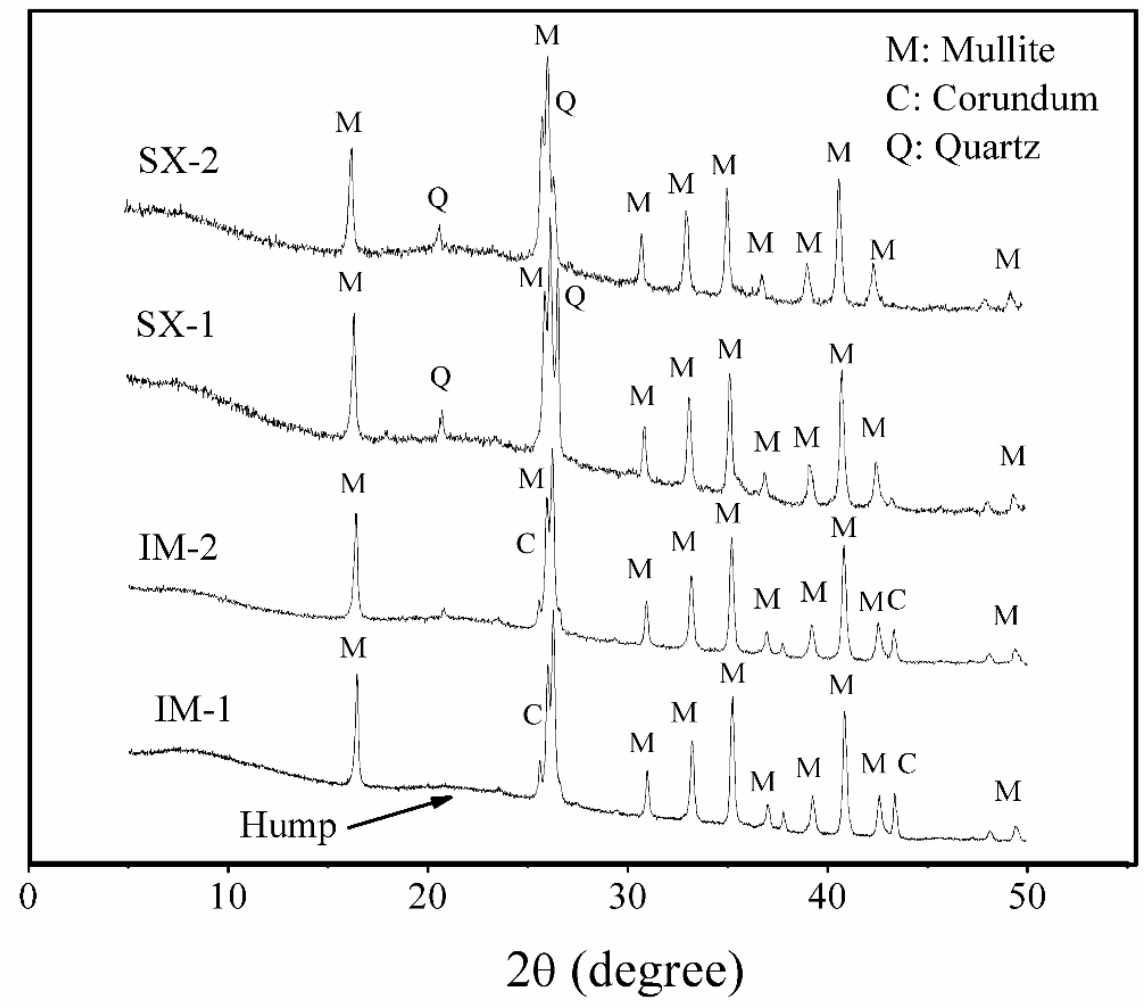

Fig. 3. XRD analysis of the HAFA

(Single fitting image)

\subsection{Distribution of $\mathrm{Li}$ in different phases of the HAFA}

Table 4

Quantitative phase analysis of the HAFA (wt. \%)

\begin{tabular}{cccc}
\hline Samples & Magnetic particles & Glass & MCQ \\
\hline
\end{tabular}




\begin{tabular}{llll}
\hline IM-1 & 1.25 & 45.01 & 53.74 \\
IM-2 & 1.14 & 37.19 & 61.66 \\
SX-1 & 6.86 & 43.13 & 50.01 \\
SX-2 & 5.09 & 41.43 & 53.49 \\
\hline
\end{tabular}

Table 4 shows that magnetic particles made up $<10 \%$ of the HAFA. In particular, the mass fractions of the magnetic particles in samples IM-1 and IM-2 were approximately $1 \%$. The fractions of the glass phase in the HAFA ranged from $37 \%$ to $45 \%$. Dai et al. (2010) quantified the minerals in different particle sizes of the HAFA using the powder XRD method. It was found that the glass phase accounted for $45-46 \%$ for particles $<42 \mu \mathrm{m}$, which is close to the IM-1 results. The MCQ was the largest fraction phase in the four HAFA samples, accounting for $>50 \%$.

\section{Table 5}

Elemental oxides and Li contents in different phases of the HAFA

\begin{tabular}{|c|c|c|c|c|}
\hline Samples & Elements & Magnetic particles & Glass & MCQ \\
\hline \multirow{8}{*}{ IM-1 } & $\mathrm{Al}_{2} \mathrm{O}_{3}$ & 30.41 & 24.87 & 72.19 \\
\hline & $\mathrm{SiO}_{2}$ & 21.11 & 61.14 & 20.82 \\
\hline & $\mathrm{Fe}_{2} \mathrm{O}_{3}$ & 36.92 & 0.95 & 1.08 \\
\hline & $\mathrm{CaO}$ & 2.33 & 6.58 & 0.09 \\
\hline & $\mathrm{TiO} 2$ & 0.85 & 3.02 & 1.64 \\
\hline & $\mathrm{MgO}$ & 0.42 & 0.25 & 0.09 \\
\hline & $\mathrm{Li}$ & 153.78 & 856.92 & 39.47 \\
\hline & LOI & 0.32 & 0 & 3.42 \\
\hline \multirow{8}{*}{ IM-2 } & $\mathrm{Al}_{2} \mathrm{O}_{3}$ & 33.92 & 13.30 & 68.93 \\
\hline & $\mathrm{SiO}_{2}$ & 29.37 & 78.19 & 25.58 \\
\hline & $\mathrm{Fe}_{2} \mathrm{O}_{3}$ & 31.02 & 1.49 & 0.54 \\
\hline & & 1.88 & 3.78 & 0.14 \\
\hline & $\mathrm{TiO} 2$ & 1.03 & 0.90 & 1.45 \\
\hline & $\mathrm{MgO}$ & 0.80 & 0.40 & 0.00 \\
\hline & $\mathrm{Li}$ & 202.53 & 934.93 & 40.97 \\
\hline & LOI & 0.82 & 0 & 2.63 \\
\hline \multirow{8}{*}{ SX-1 } & $\mathrm{Al}_{2} \mathrm{O}_{3}$ & 31.38 & 13.18 & 56.97 \\
\hline & $\mathrm{SiO}_{2}$ & 40.06 & 68.38 & 31.53 \\
\hline & $\mathrm{Fe}_{2} \mathrm{O}_{3}$ & 20.51 & 2.75 & 1.37 \\
\hline & $\mathrm{CaO}$ & 3.25 & 9.34 & 0.42 \\
\hline & $\mathrm{TiO} 2$ & 0.87 & 1.17 & 1.26 \\
\hline & $\mathrm{MgO}$ & 0.47 & 0.76 & 0.17 \\
\hline & $\mathrm{Li}$ & 180.76 & 488.81 & 86.91 \\
\hline & LOI & 2.04 & 0 & 6.95 \\
\hline$S X-2$ & $\mathrm{Al}_{2} \mathrm{O}_{3}$ & 27.26 & 13.42 & 57.78 \\
\hline
\end{tabular}




\begin{tabular}{cccc}
\hline $\mathrm{SiO}_{2}$ & 37.21 & 76.98 & 30.51 \\
$\mathrm{Fe}_{2} \mathrm{O}_{3}$ & 29.56 & 1.40 & 1.27 \\
$\mathrm{CaO}$ & 2.18 & 3.39 & 0.17 \\
$\mathrm{TiO} 2$ & 1.01 & 1.66 & 1.76 \\
$\mathrm{MgO}$ & 1.08 & 0.58 & 0.13 \\
$\mathrm{Li}$ & 156.45 & 554.93 & 54.65 \\
$\mathrm{LOI}$ & 0.18 & 0 & 7.23 \\
\hline
\end{tabular}

The contents of oxides and $\mathrm{Li}$ are reported in wt. $\%$ and $\mu \mathrm{g} / \mathrm{g}$, respectively. LOI is reported in wt. \%. The elemental oxides and $\mathrm{Li}$ contents in the glass phase were determined using Eq. 4.

Table 5 shows that the contents of $\mathrm{Al}_{2} \mathrm{O}_{3}, \mathrm{SiO}_{2}$ and, $\mathrm{Fe}_{2} \mathrm{O}_{3}$ in the magnetic particles were $27-35 \%, 20-40 \%$, and $20-37 \%$, respectively, indicating that aluminosilicates may be associated with iron oxide (Kutchko and Kim, 2006). The glass phase, with $\mathrm{SiO}_{2}$ contents of $60-80 \%$ and $\mathrm{Al}_{2} \mathrm{O}_{3}$ contents of $13-25 \%$, suggests that the main network of the glass consisted of amorphous $\mathrm{SiO}_{2}$ that is associated with a smaller portion of $\mathrm{Al}_{2} \mathrm{O}_{3}$. We conclude that the glass phase of the HAFA was dominantly composed of amorphous aluminosilicate, with total $\mathrm{SiO}_{2}$ and $\mathrm{Al}_{2} \mathrm{O}_{3}$ contents of 81.5-95.5\%. In MCQ, $\mathrm{Al}_{2} \mathrm{O}_{3}$ and $\mathrm{SiO}_{2}$ were the dominant elements with a total percentage of $88-94 \%$. The mass ratios of $\mathrm{Al}_{2} \mathrm{O}_{3}$ to $\mathrm{SiO}_{2}$ in the MCQ phases of IM-1 and IM-2 were higher than the ratios in the MCQ phases of SX-1 and SX-2. This can be explained by the presence of corundum and the absence of quartz in samples IM-1 and IM-2. 


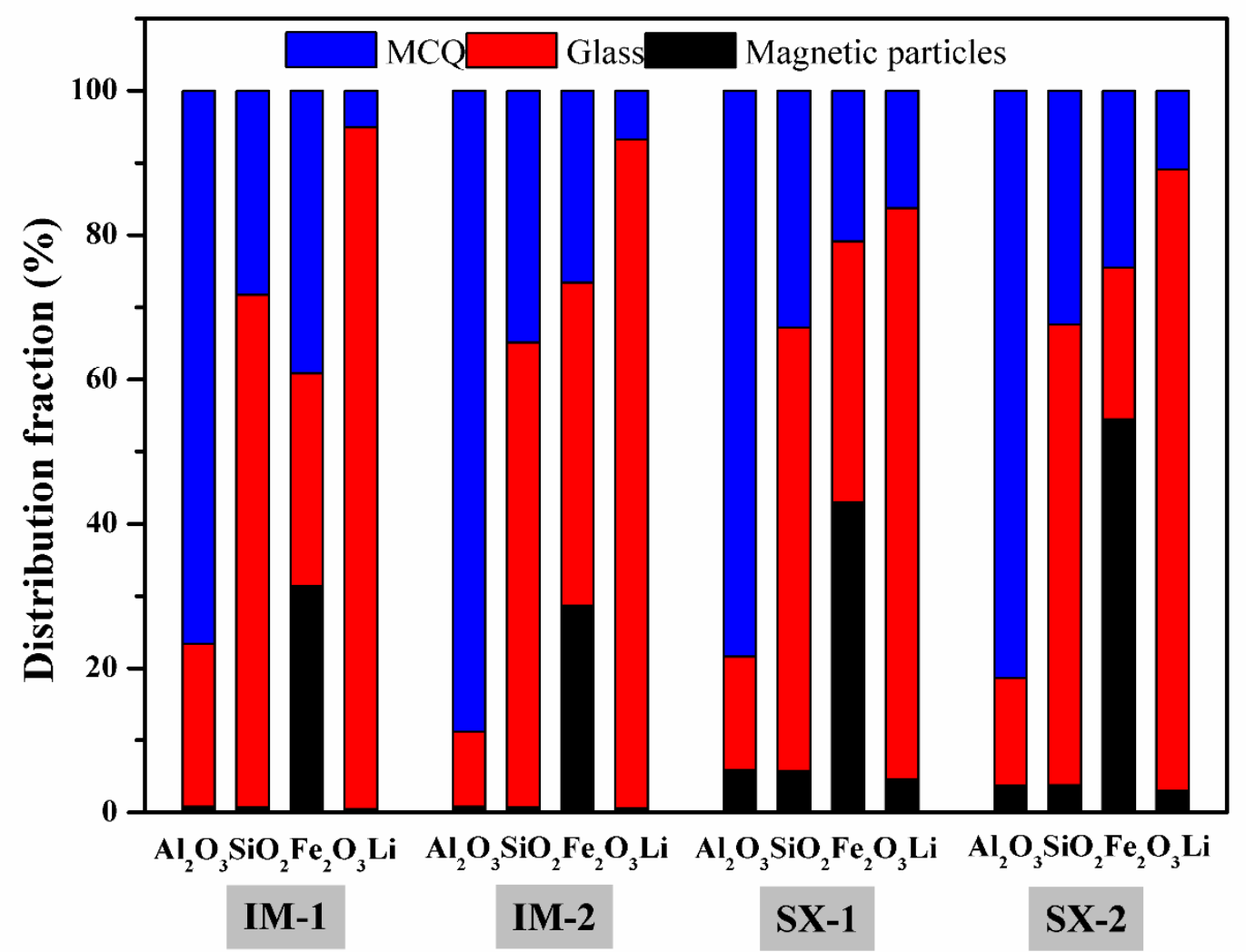

Fig. 4. Elemental oxides and Li distributions in different phases of the HAFA (wt. \%) (Single fitting image)

As shown in Fig. 4, the majority of $\mathrm{Al}_{2} \mathrm{O}_{3}$ (77-87\%) was accumulated in the MCQ phase. Most $\mathrm{SiO}_{2}(61-71 \%)$ was distributed in the glass phase. According to the XRD patterns of HAFA in Fig. 2, Al mainly existed in the HAFA in the form of mullite, whereas Si mainly existed in the HAFA in the form of amorphous $\mathrm{Si}$ in the glass phase. As one of the most problematic impurities in the recovery process of $\mathrm{Al}$, the $\mathrm{Si}$ in the glass phase should be removed prior to the extraction of $\mathrm{Al}$, considering the active properties of glass and the stable properties of MCQ (Zhu et al., 2013). $\mathrm{Fe}_{2} \mathrm{O}_{3}$ was uniformly distributed in the three phases of IM-1, whereas $\mathrm{Fe}_{2} \mathrm{O}_{3}$ was more distributed in the glass phase in IM-2, and in magnetic particles in SX-1 and SX-2. 79-94\% Li occurred in glass, only 5-16\% Li occurred in MCQ, and $<5 \% \mathrm{Li}$ occurred in magnetic particles. It is inferred that most of the Li can be leached along with the dissolution of the glass phase. 


\subsection{Chemical state imaging of $\mathrm{Li}$ in the HAFA}

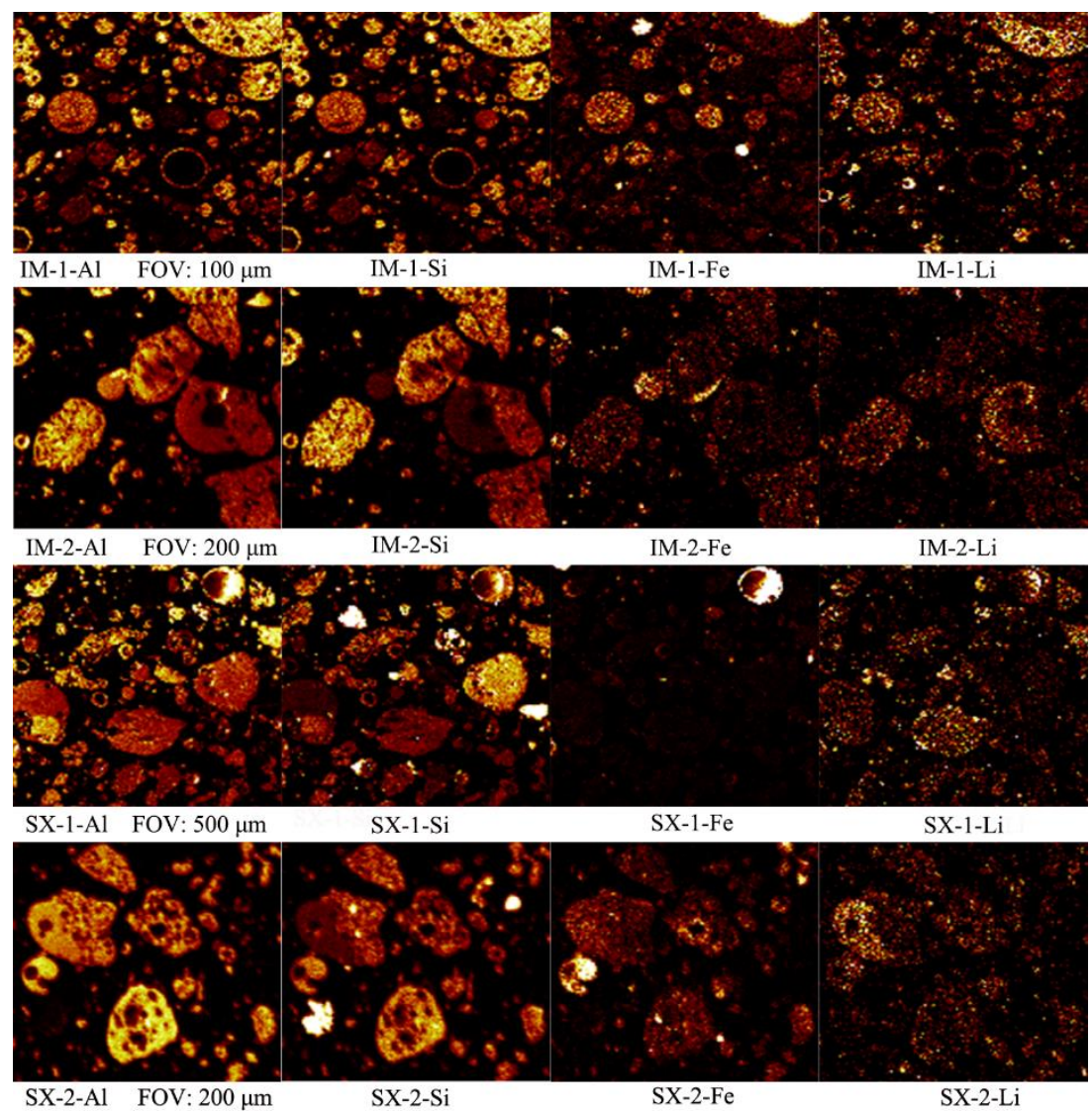

Fig. 5. TOF-SIMS images of $\mathrm{Al}, \mathrm{Si}$, Fe, and $\mathrm{Li}$ performed on the HAFA particles (1.5-column fitting image)

Fig. 5 shows TOF-SIMS images of the HAFA particles. Al and $\mathrm{Si}$, as the two dominant elements in HAFA, presented a clear morphology of the cross-sections of the HAFA particles. It was found that the HAFA consisted of spheres, ellipsoids, and irregular particles of various sizes. Most of the particles contain small bubbles. Such hollow ash particles, which are called cenospheres, are typical particles found in fly ash (Kolay and Bhusal, 2014). The differences between the images of Al and Si were possibly caused by the presence of corundum and quartz in the HAFA. The highlighted particles in the Si images of SX-1 and SX-2 are ascribed to the presence of quartz. Fe was found to co-exist with $\mathrm{Al}$ and $\mathrm{Si}$ in the HAFA. Some Fe was extremely enriched in a few particles. In general, $\mathrm{Li}$ was relatively uniformly distributed in particles, showing a correlation with the distributions of $\mathrm{Al}$ and $\mathrm{Si}$. $\mathrm{Li}$ 
did not exist in quartz given that there were no Li detections at the positions where quartz occurred. We deduce that Li may co-exist with $\mathrm{Al}$ and $\mathrm{Si}$ in mullite, magnetic particles and the glass phase.

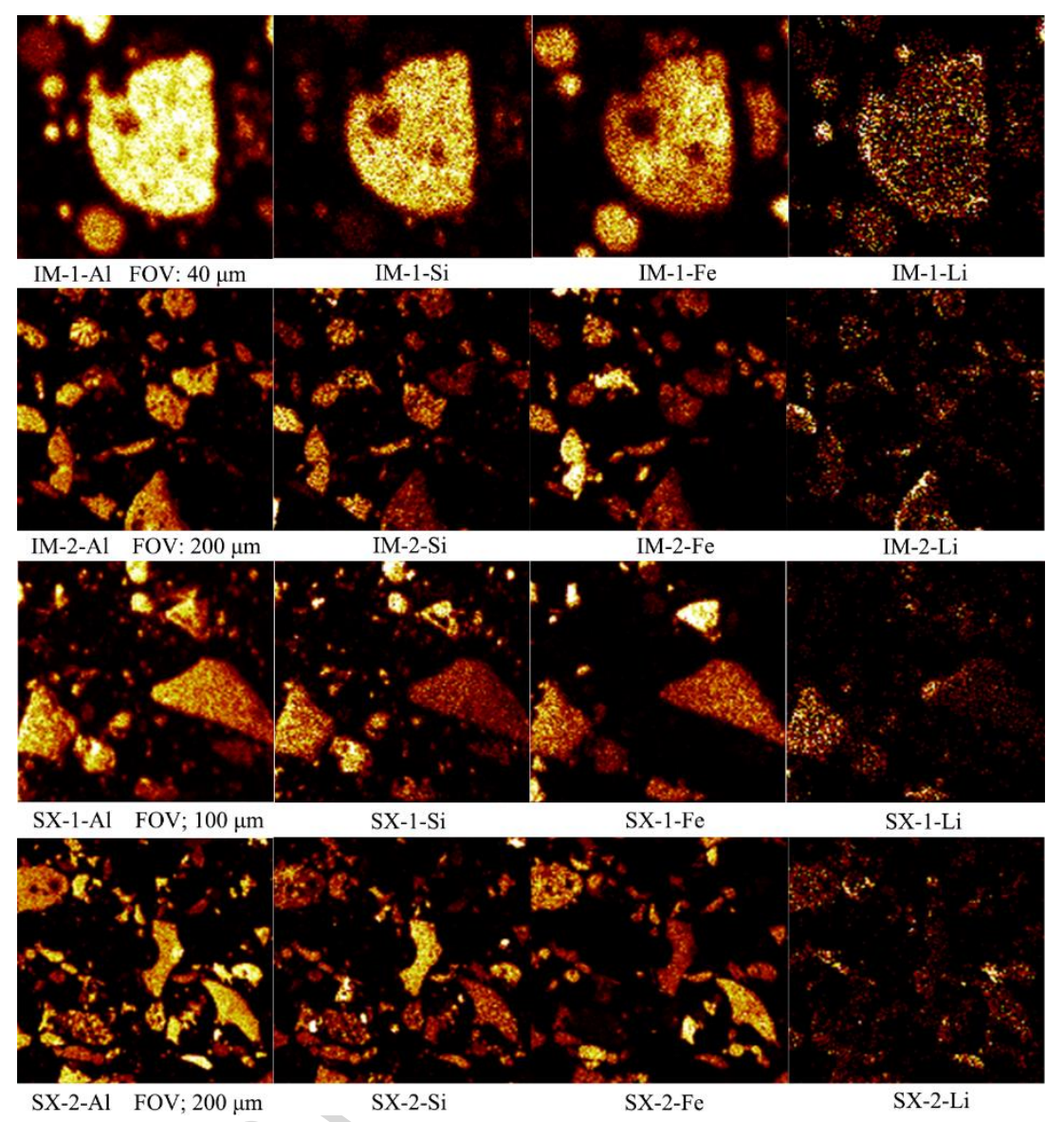

Fig. 6. TOF-SIMS images of $\mathrm{Al}, \mathrm{Si}, \mathrm{Fe}$, and $\mathrm{Li}$ performed on the magnetic spheres (1.5-column fitting image)

Fig. 6 shows TOF-SIMS images of the magnetic particles. It shows that the content of $\mathrm{Fe}$ in the magnetic particles was comparable to the contents of $\mathrm{Al}$ and $\mathrm{Si}$, according to the brightnesses of the images. The image of Fe in the magnetic particles was highly relevant to the images of $\mathrm{Al}$ and $\mathrm{Si}$. Similarly, Li co-existed with Al, Si, and $\mathrm{Fe}$ in the magnetic particles. The fraction of $\mathrm{Li}$ in magnetic particles might be negligible given the small fraction of magnetic particles in the HAFA. 

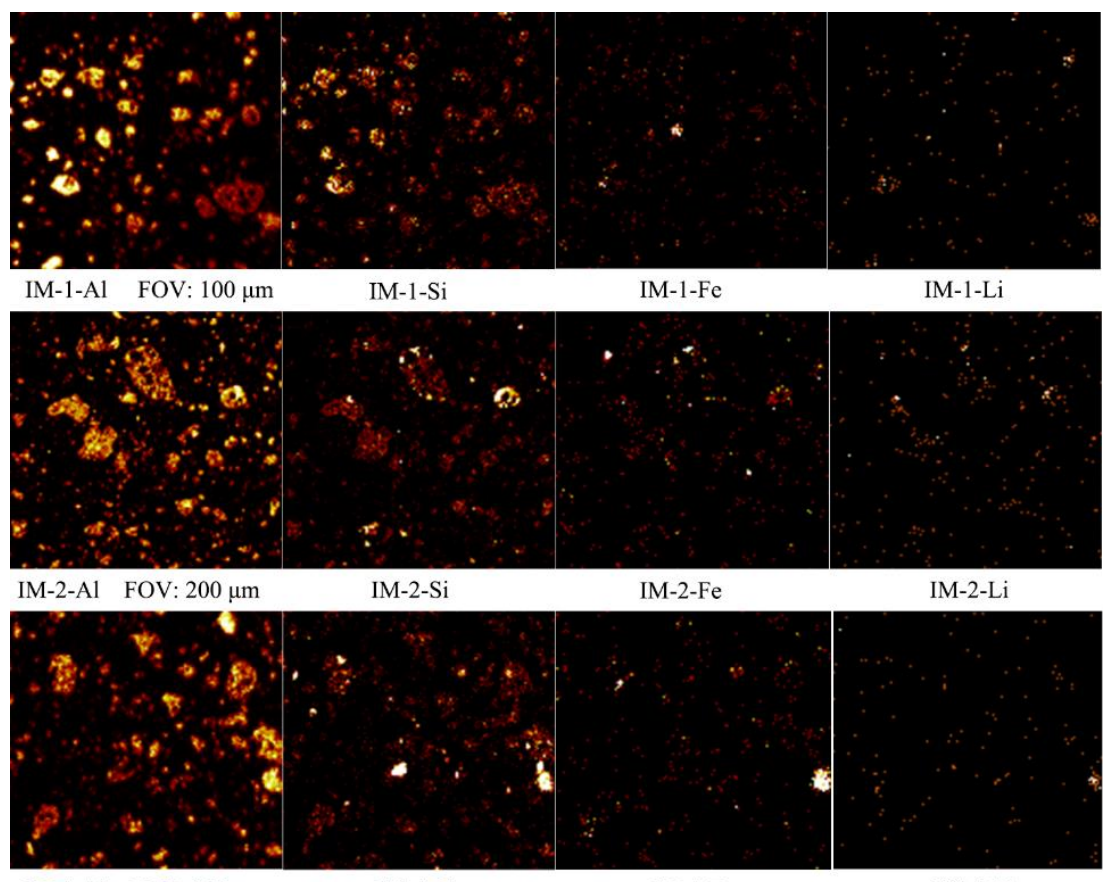

SX-1-Al FOV: $100 \mu \mathrm{m}$

$\mathrm{SX}-1-\mathrm{Si}$

$\mathrm{SX}-1-\mathrm{Fe}$

$\mathrm{SX}-1-\mathrm{Li}$

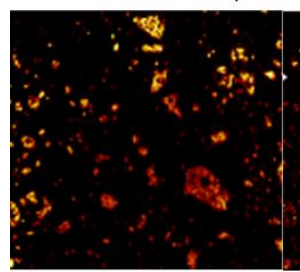

SX-2-Al FOV: $200 \mu \mathrm{m}$

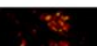

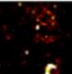

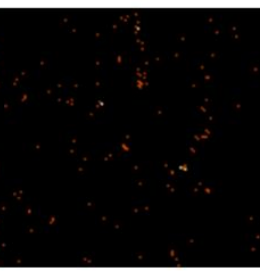

$\mathrm{SX}-2-\mathrm{Si}$

$\mathrm{SX}-2-\mathrm{Li}$

Fig. 7. TOF-SIMS images of $\mathrm{Al}, \mathrm{Si}$, Fe, and Li performed on the MCQ phase (1.5-column fitting image)

Fig. 7 shows TOF-SIMS images of the MCQ phase. It shows that the cenospheres that were present in the HAFA were rare in this fraction, indicating that cenospheres constitute much of the glass phase. Al was a major component in MCQ with the brightest and clearest particle images. The images of Si were similar to the images of Al. Some highlighted particles in the Si images for samples IM-2, SX-1, and SX-2 might be quartz. Fe was still enriched in some of the particles. Li was barely detected in the MCQ phase.

From the observations above, we conclude that $\mathrm{Li}$ may exist in magnetic particles and the glass phase, and rarely exists in MCQ. Considering the small mass fraction of magnetic particles, most $\mathrm{Li}$ is deduced to occur in the glass phase, which is consistent with the results shown in Fig. 4. 


\subsection{Occurrence of $\mathrm{Li}$ in the glass phase of HAFA}

According to Sun's Single Bond Strength Criterion (Sun, 1947), Si and Al are classified as glass formers (backbone of the glass), whereas $\mathrm{Li}$ is classified as a glass modifier (occupies interstitial sites). A formation pathway of Li in silicate glass has been previously proposed (Varshneya, 1994). Li enters the glass as singly charged cations and occupies interstitial sites. This is accomplished by breaking a bridge and attaching an oxygen atom to the broken bridge, as shown by Rea. 1. It has been found that an increase in $\mathrm{Li}_{2} \mathrm{O}$ content contributes to breaking the glass network of lithium aluminosilicate glass and increases in non-bridging oxygen (Hu et al., 2011).

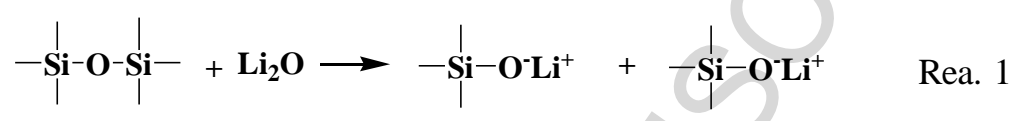

The glass phase in HAFA comprises aluminosilicates. It is deduced that Li occurs in the glass phase of HAFA as a glass modifier. Li might occupy interstitial sites, forming non-bridging oxygen by breaking bridging oxygen.
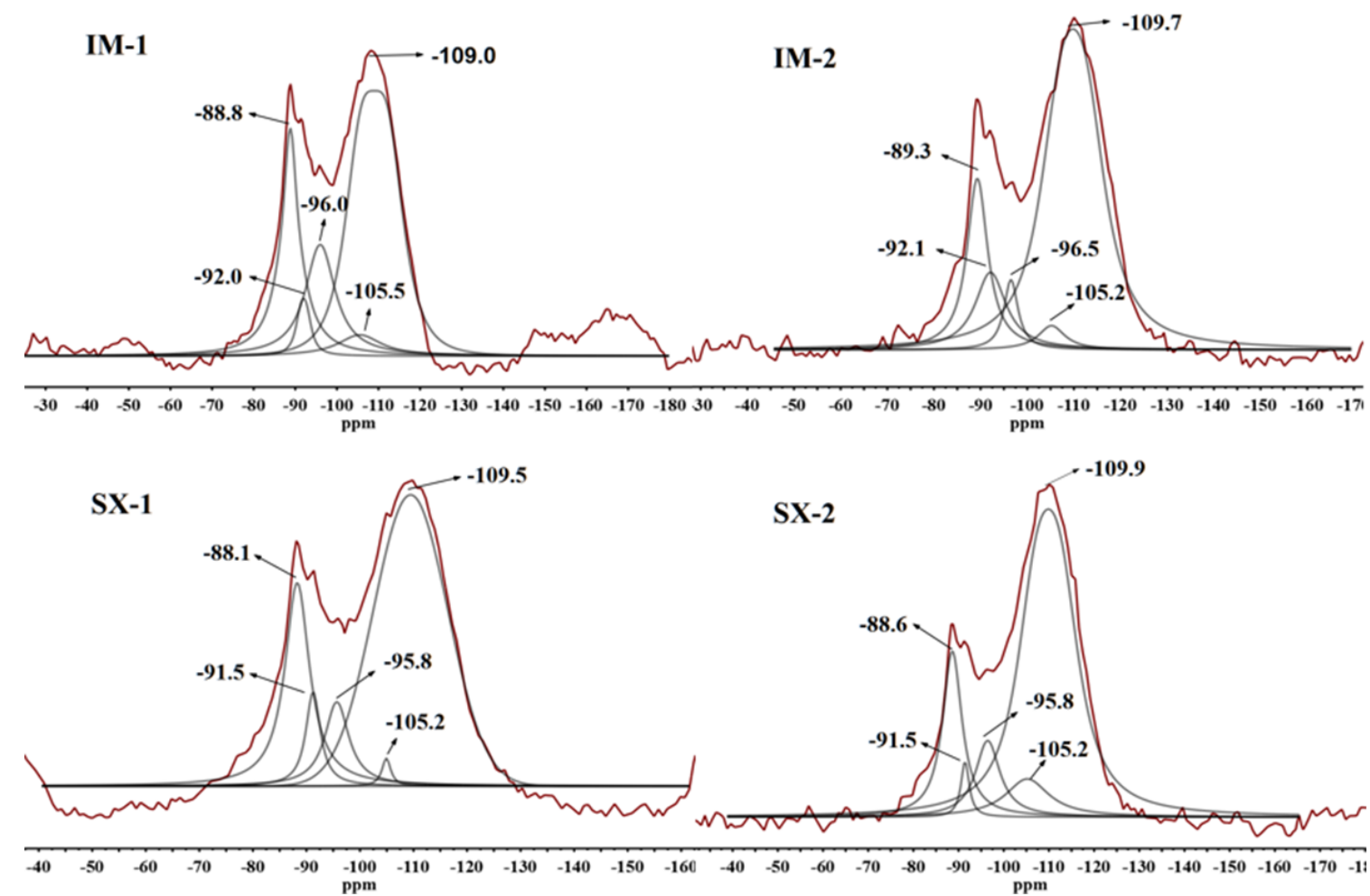


\section{Fig. 8. ${ }^{29}$ Si MAS NMR spectra of the HAFA samples}

(Single fitting image)

Fig. 8 shows the ${ }^{29}$ Si MAS NMR spectra of HAFA samples IM-1, IM-2, SX-1, and SX-2. The positions and intensities of the four peaks are roughly similar. The deconvolutions of the spectrums show the presence of five components in the HAFA. The peak at approximately $-89 \mathrm{ppm}$ is ascribed to mullite (Angel et al., 2004). The peak at approximately $-109 / 110 \mathrm{ppm}$ represents amorphous $\mathrm{SiO}_{2}\left(\mathrm{Q}^{4}\left(0 \mathrm{Al}^{*}\right)\right.$ or quartz (Angel et al., 2004). Because quartz accounts for a small mass fraction of the HAFA, the peak at $-109 / 110$ ppm mainly represents amorphous $\mathrm{SiO}_{2}$. The strong intensities of the peaks at approximately $-89 \mathrm{ppm}$ and $-109 / 110 \mathrm{ppm}$ reflect that mullite and amorphous $\mathrm{SiO}_{2}$ are the main forms of $\mathrm{Si}$ in HAFA. The peaks at approximately -92 ppm, -96 ppm, and -105 ppm correspond to $\mathrm{Q}^{4}(3 \mathrm{Al}), \mathrm{Q}^{4}(2 \mathrm{Al})$, and $\mathrm{Q}^{4}(1 \mathrm{Al})$ structures in the glass phase, respectively (Fernández-Jiménez et al., 2017; Gao et al., 2017).

To study the reaction ability of $\mathrm{Li}_{2} \mathrm{O}$ with $\mathrm{Q}^{4}(0 \mathrm{Al}), \mathrm{Q}^{4}(1 \mathrm{Al}), \mathrm{Q}^{4}(2 \mathrm{Al})$, and $\mathrm{Q}^{4}(3 \mathrm{Al})$ components in the glass phases of HAFA, model compounds of the four components were built, and the possible reactions of $\mathrm{Li}_{2} \mathrm{O}$ with the four model compounds were proposed (shown in Fig. 9). The $\Delta \mathrm{E}$ for each reaction was calculated using the GGA/PW91 method. As Table 6 shows, the proposed reactions are all possible with negative values of $\Delta \mathrm{E}$, and $\mathrm{Li}_{2} \mathrm{O}$ tends to break the $\mathrm{Si}-\mathrm{O}-\mathrm{Si}$ bond rather than the Si-O-Al bond. In particular, reactions $\mathrm{R} \_0 \mathrm{Al} \_1$ and $\mathrm{R} \_1 \mathrm{Al} \_1$ possess the lowest $\Delta \mathrm{E}$, suggesting that $\mathrm{Li}_{2} \mathrm{O}$ has a tendency to react with $\mathrm{Q}^{4}(0 \mathrm{Al})$ and $\mathrm{Q}^{4}(1 \mathrm{Al})$ components rather than $\mathrm{Q}^{4}(3 \mathrm{Al})$ and $\mathrm{Q}^{4}(2 \mathrm{Al})$ components. As a result, Li occurs more in $\mathrm{Q}^{3}(0 \mathrm{Al})$ and $\mathrm{Q}^{3}(1 \mathrm{Al})$ structures in the glass phase of HAFA.

\section{Table 6}

Energies for components $(\mathrm{Ha} / \mathrm{mol})$ and energy difference between products and reactants $(\Delta \mathrm{E})$ (kJ/mol) calculated using the GGA/PW91 method

\begin{tabular}{cccccc}
\hline Reactions & $\mathrm{E}_{\text {Reactant_1 }}$ & $\mathrm{E}_{\text {Reactant_2 }}$ & $\mathrm{E}_{\text {Product_1 }}$ & $\mathrm{E}_{\text {Product_2 }}$ & $\Delta \mathrm{E}$ \\
\hline R_0Al_1 & -2659.64 & -90.29 & -2149.97 & -600.04 & -187.97 \\
R_1Al_1 & -2536.71 & -90.29 & -2027.04 & -600.04 & -182.11 \\
R_1Al_2 & -2536.71 & -90.29 & -2149.98 & -477.07 & -109.77
\end{tabular}

\footnotetext{
${ }^{*} \mathrm{Q}^{\mathrm{n}}(\mathrm{mAl})$ sites: $\mathrm{n}, \mathrm{m}=0-4$, where $\mathrm{Q}^{\mathrm{n}}$ are connected via $\mathrm{n}$ bridging $\mathrm{O}$ atoms to $\mathrm{mAl}$.
} 


\begin{tabular}{llllll} 
R_2Al_1 & -2413.78 & -90.29 & -1904.09 & -600.04 & -160.81 \\
R_2Al_2 & -2413.78 & -90.29 & -2027.04 & -477.07 & -116.52 \\
R_3Al_1 & -2290.87 & -90.29 & -1781.19 & -600.04 & -155.72 \\
R_3Al_2 & -2290.87 & -90.29 & -1904.13 & -477.07 & -99.35 \\
\hline
\end{tabular}

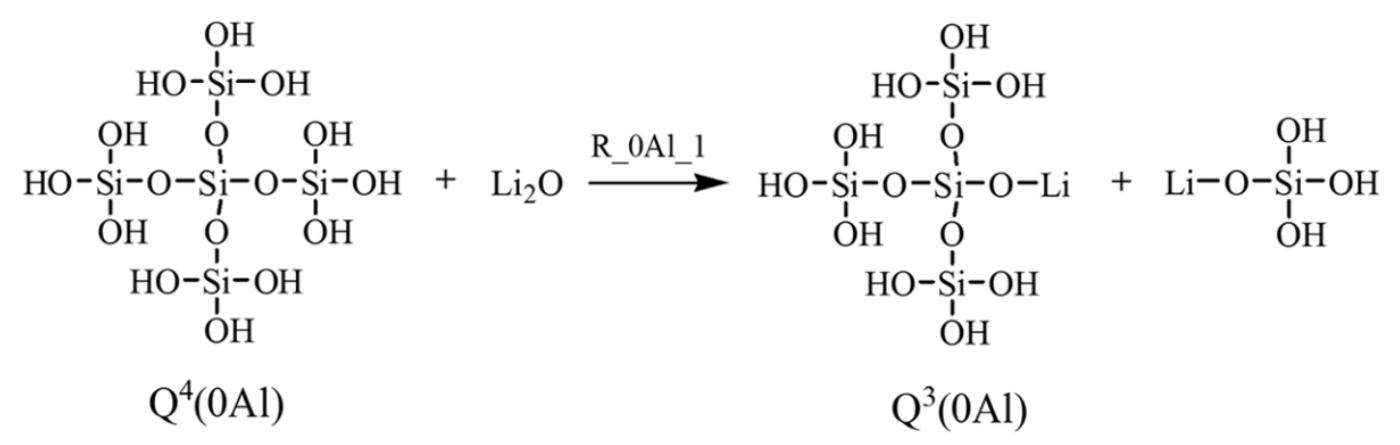

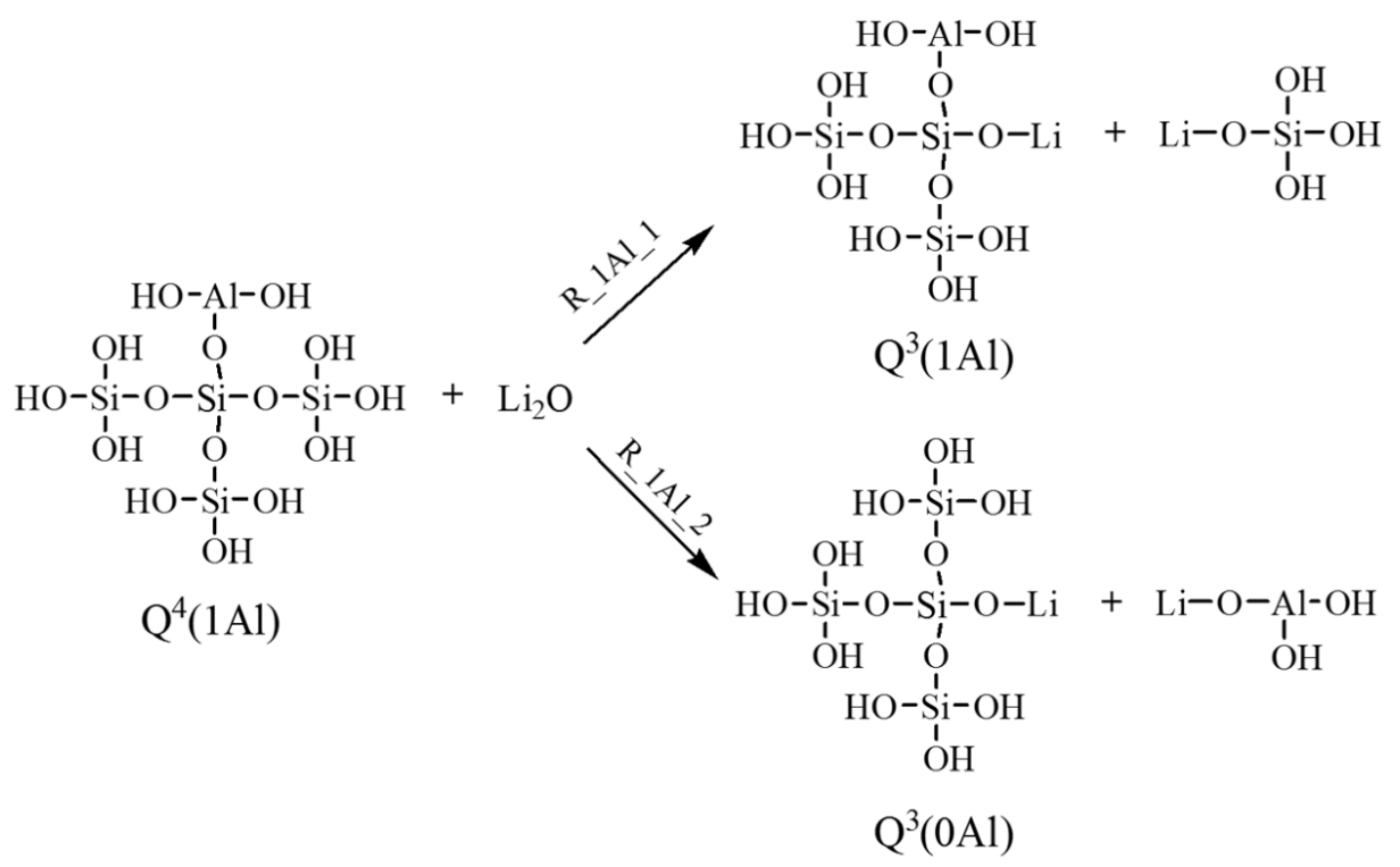




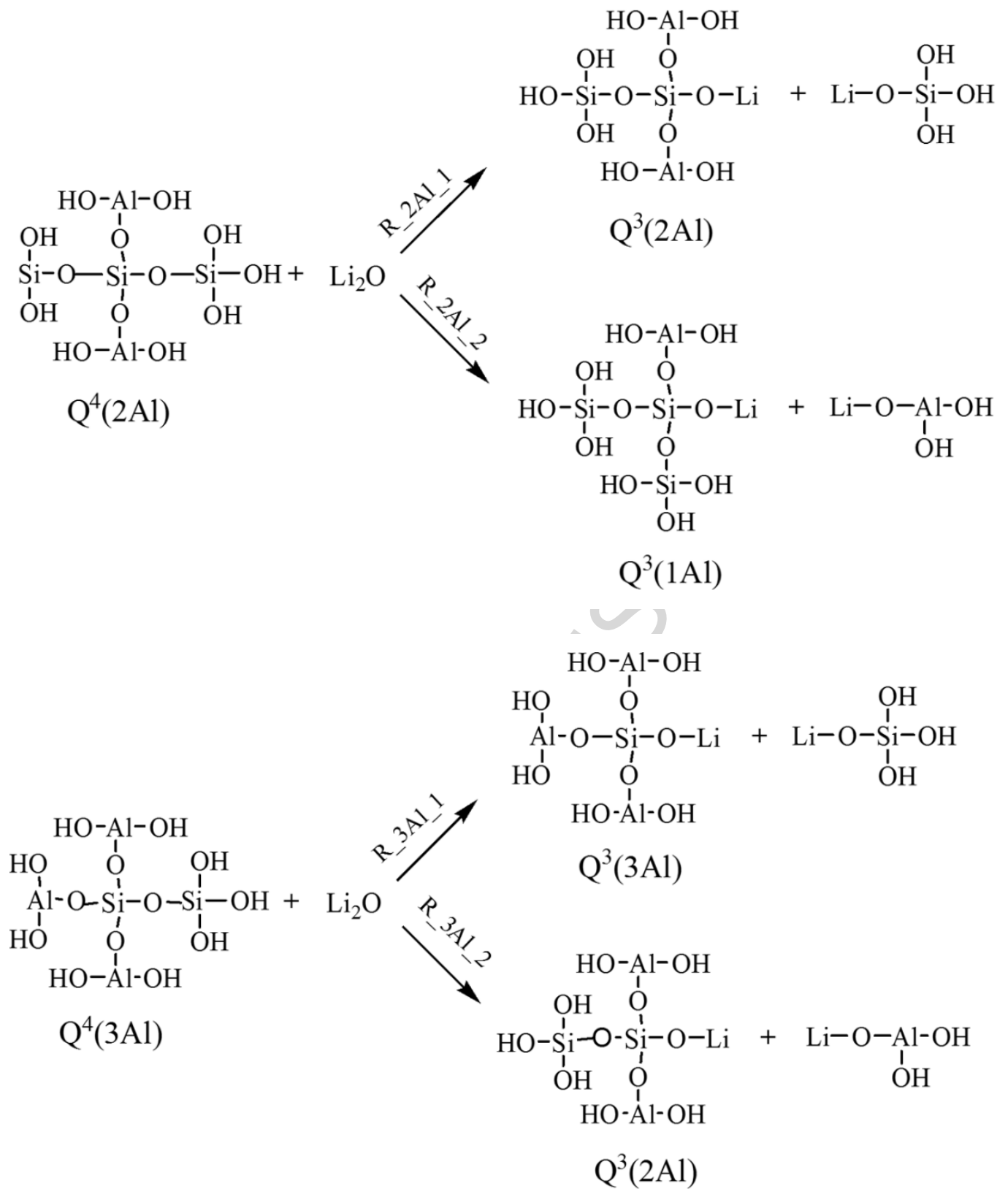

Fig. 9. Possible reactions of $\mathrm{Li}_{2} \mathrm{O}$ with the four model compounds in the glass phase of HAFA (Single fitting image)

\section{Practical implications}

According to the TOF-SIMS analysis, Li is uniformly distributed not only in most of the particles but also in the interior of HAFA particles. Therefore, it will be difficult to extract $\mathrm{Li}$ from HAFA using physical methods such as floatation and gravity separation. Pre-desilication is a key process in the recovery of Al from HAFA. It is intended to remove active silicon before the extraction of Al by dissolving the glass 
phase in HAFA in addition with a $\mathrm{NaOH}$ solution at $<100^{\circ} \mathrm{C}$ (Du et al., 2011). Based on the present study, most Li may mainly exist as a glass modifier in the glass phase of HAFA. Li is very likely to be leached into the pre-desilication solution when the glass phase is decomposed. We therefore suggest improving the pre-desilication process to elevate the leaching efficiency of $\mathrm{Li}$, and then separate the $\mathrm{Li}$ from the pre-desilication solution. In that way, the Al and Li can be co-extracted. The process is shown in Fig. 10.

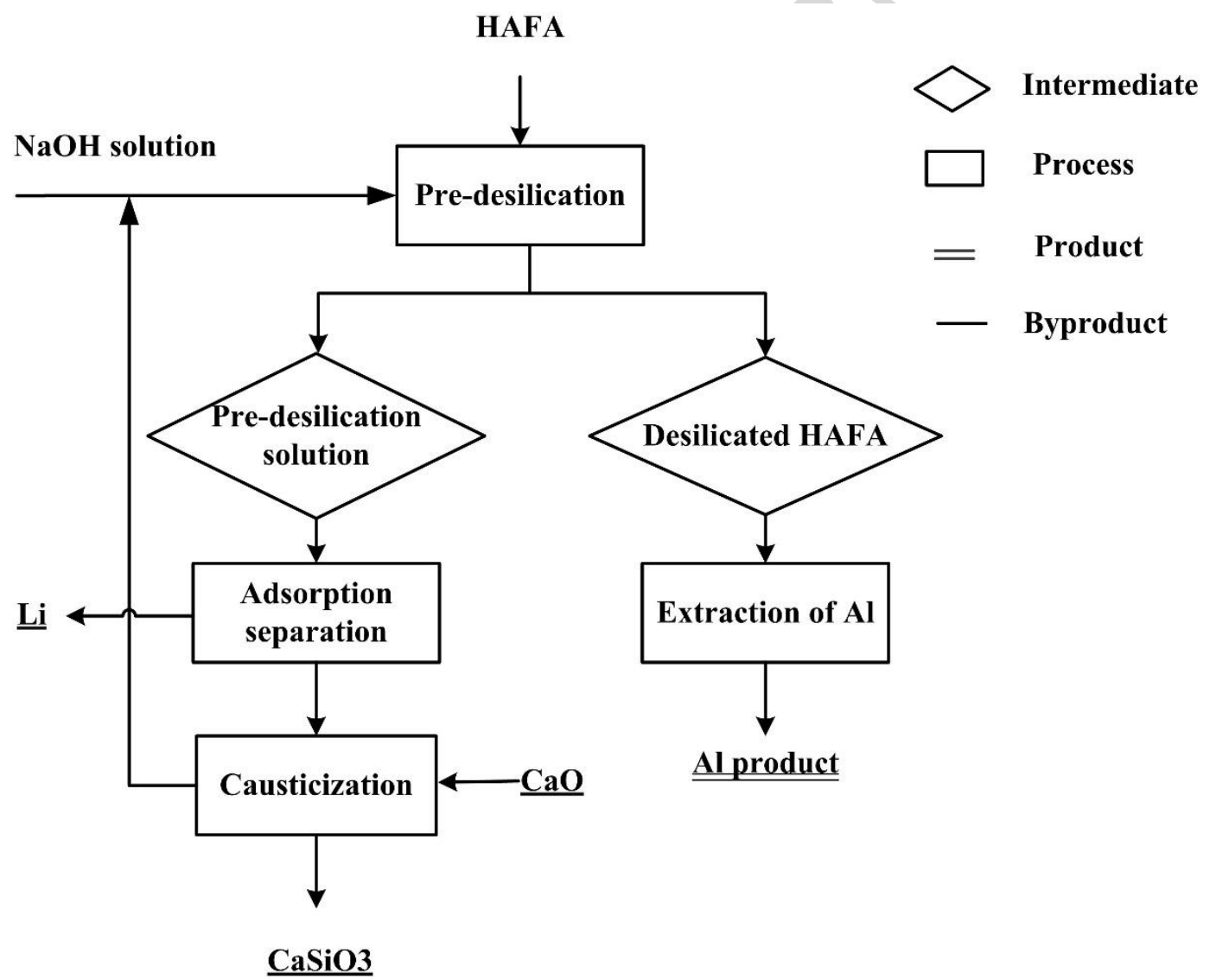

Fig. 10. Recovery process of lithium and alumina from HAFA

(Single fitting image)

\section{Conclusions}

Based on sequence separation of the HAFA and chemical analyses of the separation products, $79-94 \% \mathrm{Li}$ was observed in the glass phase, with the remaining 
$5-16 \%$ and $<5 \%$ of $\mathrm{Li}$ found in MCQ and magnetic particles. TOF-SIMS analyses showed that Li was relatively uniformly distributed in HAFA particles, and was strongly correlated with $\mathrm{Al}$ and $\mathrm{Si}$. From the energy differences between products and reactants $(\Delta \mathrm{E})$ that were calculated using the GGA/PW91 method, it was found that $\mathrm{Li}_{2} \mathrm{O}$ has a tendency to react with $\mathrm{Q}^{4}(1 \mathrm{Al})$ and $\left.\mathrm{Q}^{4}(0 \mathrm{Al})\right)$ components, resulting in more $\mathrm{Li}$ occurring in $\mathrm{Q}^{3}(\mathrm{Al})$ and $\mathrm{Q}^{3}(1 \mathrm{Al})$ structures. In addition, $\mathrm{Li}_{2} \mathrm{O}$ tends to break $\mathrm{Si}-\mathrm{O}-\mathrm{Si}$ bonds, rather than $\mathrm{Si}-\mathrm{O}-\mathrm{Al}$ bonds. Finally, $\mathrm{Li}$ is suggested to be extracted during the pre-desilication process by dissolving the glass phase. 


\section{Acknowledgements}

This research was supported by National Key R\&D Program of China (2017YFB0603102); Shanxi Province Coal Based Low-carbon Technology Major Projects (MC2016-05); and Jiangsu Collaborative Innovation Center for Ecological Building Materials and Environmental Protection Equipments / Yancheng Institute of Technology / Key Laboratory for Advanced Technology in Environmental Protection of Jiangsu Province (YCXT201612). The molecular simulation results described in this paper were obtained on the Deepcomp7000 at the Supercomputing Center in the Computer Network Information Center of the Chinese Academy of Sciences. The TOF-SIMS analyses were performed at the Analys is Center Tsinghua University.

\section{References}

Angel, P., Santiago, A., Ana, F.-J., 2004. Alkaline Activation of Fly Ashes: NMR Study of the Reaction Product. Journal of the American Ceramic Society 87, 1141-1145.

Chen, J.-F., 2005. Characterization of high-alumina fly ash and its use in synthesis of mullite: A case from the Jungar power plant in Inner Mongolia, northern China. China University of Mining and Technology (Beijing), p. 42.

Chen, T., Zhuang, J., Zhan, L., Wang, J., Feng, Y., 2017. Extraction of Iron from Fly Ash by Wet-Dry Magnetic Separation. Mining and Metallurgical Engineering $37,60-63$.

Dai, S., Finkelman, R.B., 2017. Coal as a promising source of critical elements: Progress and future prospects. International Journal of Coal Geology, http://dx.doi.org/10.1016/j.coal.2017.06.005.

Dai, S., Jiang, Y., Ward, C.R., Gu, L., Seredin, V.V., Liu, H., Zhou, D., Wang, X., Sun, Y., Zou, J., Ren, D., 2012a. Mineralogical and geochemical compositions of the coal in the Guanbanwusu Mine, Inner Mongolia, China: Further evidence for the existence of an Al (Ga and REE) ore deposit in the Jungar Coalfield. International Journal of Coal Geology 98, 10-40. 
Dai, S., Li, D., Chou, C.-L., Zhao, L., Zhang, Y., Ren, D., Ma, Y., Sun, Y., 2008. Mineralogy and geochemistry of boehmite-rich coals: New insights from the Haerwusu Surface Mine, Jungar Coalfield, Inner Mongolia, China. International Journal of Coal Geology 74, 185-202.

Dai, S., Ren, D., Chou, C.-L., Li, S., Jiang, Y., 2006. Mineralogy and geochemistry of the No. 6 Coal (Pennsylvanian) in the Junger Coalfield, Ordos Basin, China. International Journal of Coal Geology 66, 253-270.

Dai, S., Ren, D., Yang, J., Zhang, W., Jiao, F., 2000. TOF-SIMS study of the hydrocarbon-generating potential of mineral-bituminous groundmass. ACTA Geologica Sinica 74, 84-92.

Dai, S., Zhao, L., Peng, S., Chou, C.-L., Wang, X., Zhang, Y., Li, D., Sun, Y., 2010. Abundances and distribution of minerals and elements in high-alumina coal fly ash from the Jungar Power Plant, Inner Mongolia, China. International Journal of Coal Geology 81, 320-332.

Dai, S., Zou, J., Jiang, Y., Ward, C.R., Wang, X., Li, T., Xue, W., Liu, S., Tian, H., Sun, X., Zhou, D., 2012b. Mineralogical and geochemical compositions of the Pennsylvanian coal in the Adaohai Mine, Daqingshan Coalfield, Inner Mongolia, China: Modes of occurrence and origin of diaspore, gorceixite, and ammonian illite. International Journal of Coal Geology 94, 250-270.

Du, Z., Li, H., Bao, W., Li, S., Weiquan, C., 2011. Reaction Mechanism of Desilification Process of High Aluminum Fly Ash by Alkali Solution. The Chinese Journal of Process Engineering 11, 442-447.

Fernández-Jiménez, A., Cristelo, N., Miranda, T., Palomo, Á., 2017. Sustainable alkali activated materials: Precursor and activator derived from industrial wastes. Journal of Cleaner Production 162, 1200-1209.

Gao, X., Yu, Q.L., Brouwers, H.J.H., 2017. Apply ${ }^{29} \mathrm{Si},{ }^{27} \mathrm{Al}$ MAS NMR and selective dissolution in identifying the reaction degree of alkali activated slag-fly ash composites. Ceramics International 43, 12408-12419.

Gong, B., Tian, C., Xiong, Z., Zhao, Y., Zhang, J., 2016. Mineral changes and trace element releases during extraction of alumina from high aluminum fly 
ash in Inner Mongolia, China. International Journal of Coal Geology 166, 96-107.

Hayashi, S., Takahashi, T., Kanehashi, K., Kubota, N., Mizuno, K., Kashiwakura, S., Sakamoto, T., Nagasaka, T., 2010. Chemical state of boron in coal fly ash investigated by focused-ion-beam time-of-flight secondary ion mass spectrometry (FIB-TOF-SIMS) and satellite-transition magic angle spinning nuclear magnetic resonance (STMAS NMR). Chemosphere 80, 881-887.

Hou, X., Li, Y., Dai, H., Hou, Y., 2015. Leaching of lithium from fly ash using carbonate. Journal of Hebei University of Engineering (Natural Science Edition) 32, $58-61$.

Hou, X., Ren, D., Mao, H., Lei, J., Jin, K., Chu, P.K., Reich, F., Wayne, D.H., 1995. Application of imaging TOF-SIMS to the study of some coal macerals. International Journal of Coal Geology 27, 23-32.

Hu, Y., Ding, M., Cui, Q., Ni, Y., Chunhua, L., 2011. Research on UV transmission and structure for lithium aluminosilicate glasses. Optical Technique 37, 533-537.

Kolay, P.K., Bhusal, S., 2014. Recovery of hollow spherical particles with two different densities from coal fly ash and their characterization. Fuel 117, 118-124.

Kutchko, B., Kim, A., 2006. Fly ash characterization by SEM-EDS. Fuel 85, 2537-2544.

Li, C., Li, Y., Sun, H., Li, L., 2011. The Composition of Fly Ash Glass Phase and Its Dissolution Properties Applying to Geopolymeric Materials. Journal of the American Ceramic Society 94, 1773-1778.

Li, H., Hui, J., Wang, C., Bao, W., Sun, Z., 2014. Extraction of alumina from coal fly ash by mixed-alkaline hydrothermal method. Hydrometallurgy 147-148, 183-187.

Li, S., Wu, W., Li, H., Hou, X., 2016. The direct adsorption of low concentration gallium from fly ash. Separation Science and Technology 51, 395-402.

Low, F., Zhang, L., 2012. Microwave digestion for the quantification of inorganic elements in coal and coal ash using ICP-OES. Talanta 101, 346-352.

Ortmann, F., Bechstedt, F., Schmidt, W.G., 2006. Semiempirical van der Waals 
correction to the density functional description of solids and molecular structures. Physical Review B 73.

Perdew, J.P., Burke, K., Ernzerhof, M., 1996. Generalized Gradient Approximation Made Simple. Physical Review Letters 77, 3865-3868.

Seredin, V.V., Dai, S., Sun, Y., Chekryzhov, I.Y., 2013. Coal deposits as promising sources of rare metals for alternative power and energy-efficient technologies. Applied Geochemistry 31, 1-11.

Sun, J., 2016. Resource exploitation and utilization from high aluminum coal ash and circular economy. Coal Ash Asia (CAA 2016).

Sun, K.-H., 1947. Fundamental condition of glass formation. Journal of the American Ceramic Society 30, 277-281.

Tripathy, A.K., Sarangi, C.K., Tripathy, B.C., Sanjay, K., Bhattacharya, I.N., Mahapatra, B.K., Behera, P.K., Satpathy, B.K., 2015. Aluminium recovery from NALCO fly ash by acid digestion in the presence of fluoride ion. International Journal of Mineral Processing 138, 44-48.

Varshneya, A.K., 1994. Fundamentals of Inorganic Glasses. Academic Press Inc., Harcourt Brace \& Company, Publishers, New York.

Zhang, J.-B., Li, S.-P., Li, H.-Q., He, M.-M., 2016. Acid activation for pre-desilicated high-alumina fly ash. Fuel Processing Technology 151, 64-71.

Zhang, J., Li, S., Li, H., Wu, Q., Xi, X., Li, Z., 2017. Preparation of Al-Si composite from high-alumina coal fly ash by mechanical-chemical synergistic activation. Ceramics International 43, 6532-6541.

Zhang, Z., Sun, J., He, Y., Liu, G., Wang, Y., Cao, H., 2006. Distribution of some major and trace elements in high aluminum fly ash. Geochimica 35, 660-666.

Zhu, G., Tan, W., Sun, J., Gong, Y., Zhang, S., Zhang, Z., Liu, L., 2013. Effects and Mechanism Research of the Desilication Pretreatment for High-Aluminum Fly Ash. Energy \& Fuels 27, 6948-6954. 


\section{Highlights}

- Chemical state imaging of Li in the HAFA, magnetic particles and MCQ was obtained using TOF-SIMS.

- Modes of occurrence of Li in the glass of HAFA was investigated by NMR analys is and molecular simulation.

- Lithium tends to occur in $\mathrm{Q}^{3}(0 \mathrm{Al})$ and $\mathrm{Q}^{3}(1 \mathrm{Al})$ structures in the glass of HAFA. 